\title{
Study of Lacking Picks on Shearer Helical Vane on Drum Load Influence
}

\author{
Li Xiaohuo, a, Yao Tianyu, 2, b Mu Yongcheng ${ }^{3, ~ c}$, Hu Yantao ${ }^{4, d}$ \\ 1,2,3,4 Mechanical Engineering College of Liaoning Technical University, Fuxin 123000, China
}

alixiaohuo@163.com,,yaotianyu85833@sina.com, ${ }^{\text {}}$ muyongcheng2006@sina.com, ${ }^{\text {}}$ huyantao1982 @163.com

Keywords: Drum shearer; Helical vane; Cutting pick; Load; Matlab

\begin{abstract}
In order to master load magnitude a drum and its changes under lacking picks condition, find out the influence on drum loads when lacking picks on helical vanes, explore failure reasons of a shearer drum, a mathematical model of shearer drum loads was analyzed and established in the paper, using Matlab computer analysis program, drum loads and their changes under several conditions were simulated when lacking picks on helical vanes, and the influence to shearer drum load of lacking picks on different positions was analyzed. The results indicate that, the closer lacking pick position to the seam exposed surface, the smaller drum load fluctuation is when existing one lacking pick on helical vane; the load fluctuation and position angle of two lacking picks on the drum inversely proportional when existing two lacking picks on helical vane, which is roughly in accord with the actual situation.
\end{abstract}

\section{Introduction}

Due to a bad working environment, a lacking pick phenomenon often happens during a shearer works, a shearer under lacking pick condition will affect drum work reliability, service life, cutting performance and productivity [1,2]. Research for the drum loads and their change rules when a shearer normal working have already existed [3-5], but did not see the report about loads and influences when lacking picks on a shearer. So it is important to find out drum loads and their influences on a shearer performance when lacking picks on a shearer.

\section{Calculation method of loads on shearer drum}

Pick forces on drum. The working process of shearer drum is shown as figure 1.At any moment, the loads of $i$ th pick (position Angle is $\gamma_{\mathrm{i}}$ ) [3-5] are as follows

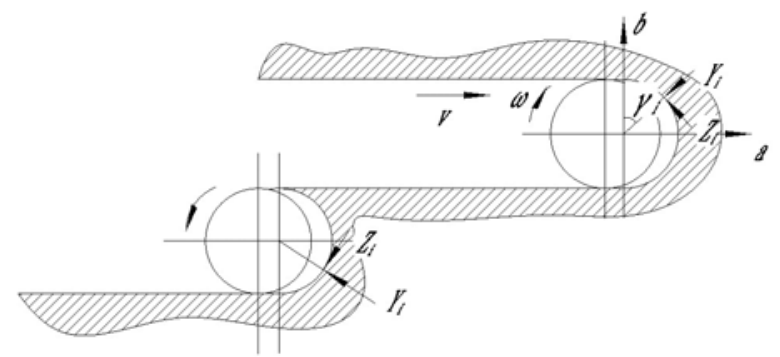

Fig. 1 Forced analysis of pick on shearer drum

(1)Cut resistance

$$
Z_{i}=10 A \frac{0.175 d+0.3}{0.5 d+B \cdot h^{0.5}} h \cdot t \cdot K_{z} \cdot K_{\varphi} \cdot K_{y} \cdot K_{c} \cdot K_{o t} \cdot K_{q} \frac{1}{\cos \theta}+100 f \cdot k_{j} \cdot \sigma_{y} \cdot S_{d} .
$$

(2)Traction resistance

$$
Y_{i}=10 A \frac{0.175 d+0.3}{0.5 d+B \cdot h^{0.5}} h \cdot t \cdot K_{z} \cdot K_{\varphi} \cdot K_{y} \cdot K_{c} \cdot K_{o t} \cdot K_{q} \frac{1}{\cos \theta}+100 k_{j} \cdot \sigma_{y} \cdot S_{d} .
$$

(3)Lateral resistance

$$
X_{i}=Z_{i} \cdot\left[\frac{C_{1}}{C_{2}+h}+C_{3}\right] \cdot \frac{h}{t}
$$


Where, $A$ is coal seam average cutting impedance; $h, t$ is respectively average cutting thickness and average transversal distance; $\sigma_{\mathrm{y}}$ is pick unidirectional compressive strength; $K_{\varphi}, K_{\mathrm{c}}, K_{\mathrm{ot}}, K_{\mathrm{q}}$ are respectively pick front influence coefficient, pick arrangement influence coefficient, mine pressure influence coefficient, ratio coefficient of traction resistance and cutting resistance.

Instantaneous drum loads. As shown in figure 1, instantaneous drum loads are vector sum of each force cutting coal and rock. Any moment $\mathrm{j}$, three directional loads of a drum (direction of vertical ' $a$ ', direction of traction ' $b$ ', axial direction of drum ' $c$ ') are

$$
R_{a j}=\sum_{i=1}^{n_{p}}\left(Y_{i} \sin \gamma_{i}+Z_{i} \cos \gamma_{i}\right), R_{b j}=\sum_{i=1}^{n_{p}}\left(-Y_{i} \cos \gamma_{i}+Z_{i} \sin \gamma_{i}\right), R_{c j}=\sum_{i=1}^{n_{p}} X_{i} .
$$

\section{Simulation of drum loads when lacking picks}

Set average cutting impedance of coal and rock for $240 \mathrm{~N} / \mathrm{mm}$. Main geometric parameters about a shearer drum are: hauling speed is $2.3 \mathrm{~m} / \mathrm{min}$, drum revolving speed is $60.5 \mathrm{r} / \mathrm{min}$, drum diameter is $1.8 \mathrm{~m}$. Pick arrangement on drum is shown in figure 2, there are three head helical vanes, installation angles of picks on helical vanes are all zero, their transversal distances are $37 \mathrm{~mm}$.

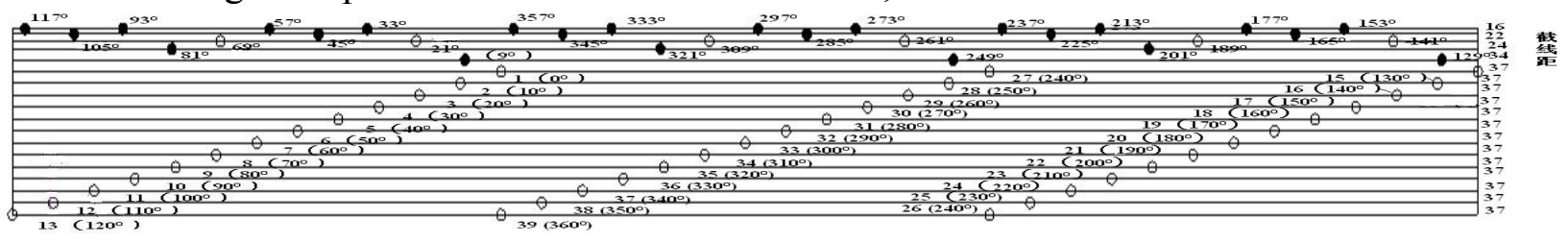

Fig. 2 Pick arrangements on drum

Lacking one picks on the same helical vane. Import lacking picks data of different positions on the helical vane (numbered $\Delta$ ) into Matlab to be simulated, and variation coefficients of drum loads are as shown in table 1.

\begin{tabular}{|c|c|c|c|c|c|c|c|}
\hline$\Delta$ & $C v a$ & $C v b$ & $C v c$ & $\Delta$ & $C v a$ & $C v b$ & $C v c$ \\
\hline 2 & 0.05875 & 0.06233 & 0.05764 & 8 & 0.04969 & 0.05465 & 0.04929 \\
\hline 3 & 0.05623 & 0.06082 & 0.05605 & 9 & 0.04938 & 0.05334 & 0.04710 \\
\hline 4 & 0.05477 & 0.05973 & 0.05519 & 10 & 0.04822 & 0.05170 & 0.04470 \\
\hline 5 & 0.05396 & 0.05862 & 0.05386 & 11 & 0.04690 & 0.05050 & 0.04228 \\
\hline 6 & 0.05243 & 0.05677 & 0.05236 & 12 & 0.04589 & 0.04799 & 0.04108 \\
\hline 7 & 0.05130 & 0.05568 & 0.05036 & Non-lacking & 0.04260 & 0.04383 & 0.03307 \\
\hline
\end{tabular}

Table 1 Load variation coefficients of lacking one pick

Lacking two picks on the same helical vane.There is research on variation coefficient of drum load when No. 2 or 3 and another pick lacking (numbered $\Delta, \Delta=4-12$ ), and variation coefficients of drum loads are as shown in table 2.

\begin{tabular}{|c|c|c|c|c|c|c|c|}
\hline$\Delta$ & $C v a$ & $C v b$ & $C v c$ & $\Delta$ & $C v a$ & $C v b$ & $C v c$ \\
\hline 2,4 & 0.08484 & 0.09125 & 0.09266 & 3,4 & 0.10048 & 0.10774 & 0.09163 \\
\hline 2,5 & 0.08130 & 0.08714 & 0.08887 & 3,5 & 0.08231 & 0.08815 & 0.08761 \\
\hline 2,6 & 0.07678 & 0.08154 & 0.08428 & 3,6 & 0.07861 & 0.08362 & 0.08580 \\
\hline 2,7 & 0.07157 & 0.07673 & 0.07911 & 3,7 & 0.07389 & 0.07907 & 0.08103 \\
\hline 2,8 & 0.06620 & 0.07113 & 0.07369 & 3,8 & 0.06872 & 0.07392 & 0.07628 \\
\hline 2,9 & 0.06216 & 0.06602 & 0.06879 & 3,9 & 0.06460 & 0.06874 & 0.07125 \\
\hline 2,10 & 0.05830 & 0.06151 & 0.06312 & 3,10 & 0.06027 & 0.06361 & 0.06533 \\
\hline 2,11 & 0.05497 & 0.05807 & 0.05836 & 3,11 & 0.05613 & 0.05942 & 0.06012 \\
\hline 2,12 & 0.05297 & 0.05517 & 0.05480 & 3,12 & 0.05327 & 0.05543 & 0.05587 \\
\hline
\end{tabular}

Table 2 Load variation coefficients of lacking two picks on same helical vane

Figure 3 is simulation curves of loads when non-lacking pick; figure 4 and figure 5 are respectively simulated curves of drum loads when lacking No.10 and lacking No.10 \& No.3. 

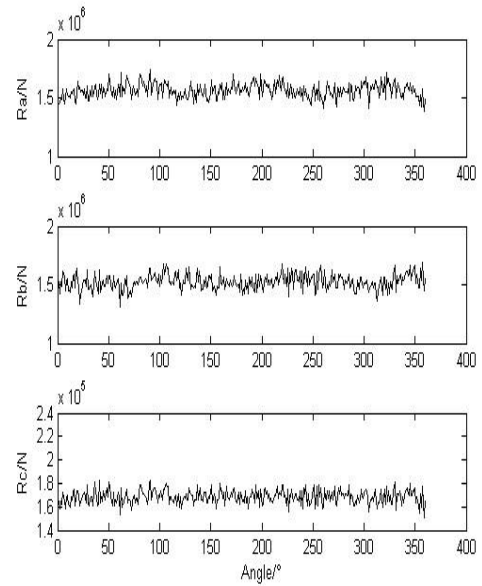

Fig. 3 Non-lacking pick
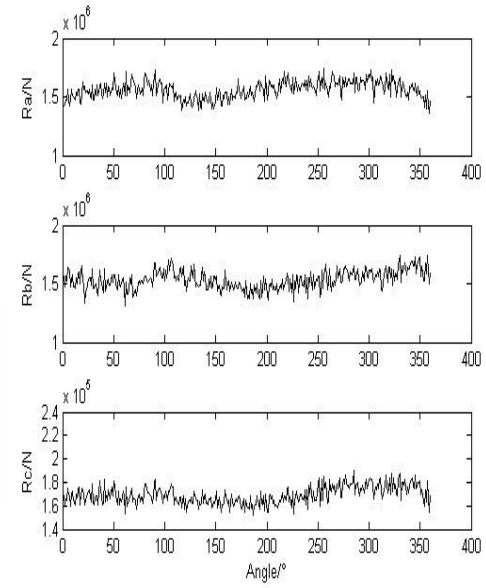

Fig. $4 \Delta=10$
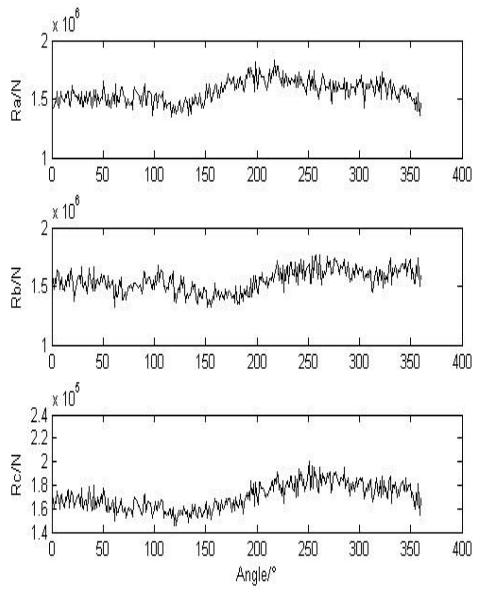

Fig. $5 \Delta=3 \& 10$

Lacking two picks on adjacent helical vane. There is research on variation coefficient of drum load when No.15 or 16 and another pick lacking $(\Delta=4-12)$, and variations coefficients of drum loads are as shown in table 3.

\begin{tabular}{|c|c|c|c|c|c|c|c|}
\hline$\Delta$ & $C v a$ & $C v b$ & $C v c$ & $\Delta$ & $C v a$ & $C v b$ & $C v c$ \\
\hline 15,4 & 0.05643 & 0.06064 & 0.06075 & 16,4 & 0.05476 & 0.05953 & 0.05674 \\
\hline 15,5 & 0.05793 & 0.06197 & 0.06373 & 16,5 & 0.05537 & 0.05970 & 0.05922 \\
\hline 15,6 & 0.05982 & 0.06384 & 0.06693 & 16,6 & 0.05624 & 0.06038 & 0.06200 \\
\hline 15,7 & 0.06270 & 0.06649 & 0.06914 & 16,7 & 0.05839 & 0.06245 & 0.06406 \\
\hline 15,8 & 0.06533 & 0.07004 & 0.07297 & 16,8 & 0.06061 & 0.06536 & 0.06771 \\
\hline 15,9 & 0.06884 & 0.07270 & 0.07401 & 16,9 & 0.06411 & 0.06804 & 0.06914 \\
\hline 15,10 & 0.07067 & 0.07469 & 0.07533 & 16,10 & 0.06626 & 0.07058 & 0.07102 \\
\hline 15,11 & 0.07188 & 0.07620 & 0.07473 & 16,11 & 0.06799 & 0.07265 & 0.07101 \\
\hline 15,12 & 0.07180 & 0.07543 & 0.07398 & 16,12 & 0.06705 & 0.07265 & 0.07092 \\
\hline
\end{tabular}

Table 3 Load variation coefficients of lacking two picks on adjacent helical vane

\section{Analysis of simulation results}

Comparing figure 4 with figure 3 finds obvious loading fluctuations. Figure 3 decreases more obviously than figure 4 in range $100^{\circ}-200^{\circ}$, while figure 3 has an obvious increasing process in $200^{\circ}$ $350^{\circ}$. Analysis shows that lacking picks should have cut coal in the range $100^{\circ}-200^{\circ}$, but lacking pick lead load on drum to decrease; the picks, which on the same transversal and next to the lacking pick, cut double thicknesses of coal lead load on drum to increase in the range $200^{\circ}-350^{\circ}$. The same situation can be reflected on the tendency between figure 4 and figure 5 .

As shown in table 1, when existing one lacking pick on drum, the closer of lacking pick to the coal seam exposed surface, the smaller coefficient variations of drum loads is. Analyzing indicates that the closer of lacking pick position to the coal exposed surface is, the smaller pressure coefficient of coal is. Then lead the decrease of influence on drum. Table 2 and table 3 show that lacking two picks on the same helical vane, horizontal or longitudinal contrast, the load variation coefficient decreases with the position angle of lacking two picks increases; when two lacking picks on adjacent helical vanes, longitudinal contrast, the variation coefficient of load first increases then decreases with the position angle of lacking two picks decreases. Owing to two lacking picks on the helical vane, the smaller position angle of lacking two picks is, the more consistent of next picks changing of cut thickness is, which on the same transversal with the lacking picks, so it adds the variation coefficient of drum load; at the same time, picks are closer to the coal exposed surface when $\Delta$ changes from 4 to 12 , such the situation is as seen in table 2 and table 3. 


\section{Conclusions}

The main reason of appearing a big load fluctuation on drum when helical vane is lack of picks is that the lacking picks don't cut coal and rock, the next pick on the same transversal will cut two cutting thicknesses of coal and rock, therefore loads change too much in certain ranges. Lacking one pick on helical vane, the closer position of lacking pick to the coal exposed surface is, the smaller load fluctuation of drum is. In addition, when lacking two picks on helical vane, three directional load fluctuations of drum mainly depend on two factors, one is the location of the two lacking picks and the other is the position angle. The smaller position angle of the lacking two picks is, the greater load fluctuation can be; the closer lacking two picks to coal seam exposed surface is, the smaller drum load fluctuation is. The research method can simulate loads on a drum and their changes accurately in the condition of lacking picks, which lays the foundation of exploring the influence to load changes on drum when lacking picks.

\section{Acknowledgements}

This work was supported by: ${ }^{1}$ National Natural Science Foundation-funded Project (59774033); ${ }^{2}$ Sci. \& tech. research guidance projects of China Coal Industry Association (MTKJ2011-325).

\section{References}

[1] Liu Songyong, Du Changlong, Cui Xinxia. The simulation analysis and investigation of the drum load spectrum of a shearer. Journal of Shandong University of Science and Technology (Natural Science), 2008, 27(1):11-13.

[2] Guo Yingfu, Zhang Yongzhong,Liu Shunde. Computer simulation of shear drum load and countermeasure of reducing load fluctuation. Mining \& Processing Equipment, 2001(5):24-26.

[3] Wang Hongying, Li Xiaohuo. Mining coal mechanical pick truncation tooth load mathematical model establishment analysis. Coal Mine Machinery, 2007, 8(4):90-92.

[4] Su Runping, An Daoxing. Computer aided design of screw rolling drum of coal mining machine. Mechanical Engineering \& Automation, 2005, 21(4):95-97.

[5] Wang Hongying, Liu Chunsheng, Wang Jinbo. The pick tine and knife tine cut force experimental analysis of coal cutter. Coal Mine Machinery, 2002, 23(6):29-31. 